\title{
FROM ECOCITY TO ECOCAMPUS: SUSTAINABILITY POLICIES IN UNIVERSITY CAMPUSES
}

\author{
L.A. SANDOVAL HAMÓN ${ }^{1}$, C.E. BAYAS ALDAZ¹ , J. RODRÍGUEZ POMEDA ${ }^{1}$, \\ F. SÁNCHEZ FERNÁNDEZ ${ }^{2}$ AND F. CASANI FERNÁNDEZ DE NAVARRETE ${ }^{1}$ \\ ${ }^{1}$ Department of Business Organization, and Research Institute on Higher Education and Science (INAECU), \\ Universidad Autónoma de Madrid. Spain. \\ ${ }^{2}$ Department of Social Psychology and Methodology, and Research Institute on Higher Education and Science \\ (INAECU), Universidad Autónoma de Madrid, Spain.
}

\begin{abstract}
Cities generate environmental impacts that have focused the global interest of scientists and authorities on the search for environment-friendly alternatives. The 'Ecocity' concept provides an innovative and sustainable vision of how to build and live in these settlements. Translating this vision to the university campus as a small-scale replica of a city is one of the challenges facing higher education institutions. Through teaching, research, outsourcing, association and university management, these institutions can promote and disseminate more advanced activities in sustainability. The purpose of this paper is to analyze the experiences in this area on two different campuses, one urban in a historic city and another suburban in the outskirts of a large city. The methodology adopts a qualitative method based on the technique of the focus group and in-depth interviews with academics and the 'Ecocampus' offices from two Spanish universities, one in an urban context and another in a suburban. The hypotheses indicate that sustainable policies in terms of setting, infrastructure, waste and water are best met by the suburban university. The sustainability efforts of the university in an urban environment stand out in energy-related indicators, transportation and education. In general, the paper suggests that higher institutions adapt their sustainability policies depending on the location of the campus; that is, in urban and suburban areas. The implications of this work addresses two perspectives, the first consists in sustainability policies of universities and the second in the contribution of these best practices to the environmental problems of the city. The originality of this study is to learn from the different experiences of sustainability policies of universities with different types of campuses and the influence of these in the development of cities.
\end{abstract}

Keywords: ecocampus, ecocity, higher education, suburban, sustainability, urban.

\section{INTRODUCTION}

The notion of Ecocity "was first proposed in 1971 as a formal scientific concept during the process of the United Nations Educational, Scientific, and Cultural Organization Man and Biosphere Program" [1]. The idea 'Ecocity' provides an innovative and sustainable vision of how to build and live in these settlements. "The framework offered by sustainability cannot only be a matter of concern at the governmental level, rather all institutions need to take an active role in achieving the goal of sustainability" [2].

This challenge also can move a small-scale amongst institutions of Higher Education. In this manner, 'universities are considered to be similar to small towns because of their large size, population, and the various complex activities taking place on campuses' [3]. Furthermore, universities and research centers have local impacts, such as employment, revenue generators, environmental management and human resources. 
In this context, universities, that have the important role of becoming places for the interchange of new ideas through teaching, researching and university's management, can promote and disseminate more advanced activities in sustainability and to be vehicles for social change.

The purpose of this study is to analyze the experiences of sustainability policies on two different campuses, one urban in a historic city and another suburban in the outskirts of a large city.

This paper is organized into five parts. First, conceptual insights from prior studies that had been focused on Ecocity and Greening of campus (Ecocampus), and with emphasis in the sustainability policies (Section 2). Second, the research methodology and an overview of the two cases which are being presented (Section 3). Finally, we present a discussion of the results in Section 4 and the conclusions in Section 5.

\subsection{Ecocity}

\section{THEORETICAL BACKGROUND}

There is a vast variety of terminology associated with 'Ecocity'; such as ecological city, green city, ecopolis, garden city and sustainable city. In fact, when the literature analyses a common definition, the authors give different points of view to understand this concept. In other words, there is not consensus with the definition of this kind of alternative city. Despite of this context, some of the most cited definitions are displayed on Table 1.

The changes of these big issues for city development require innovation and cooperation of the different agents of the community.

Table 1:Ecocitydefinitions.

\begin{tabular}{ll}
\hline \multicolumn{1}{c}{ Author(s) } & \multicolumn{1}{c}{ Definition } \\
\hline Register [4] & $\begin{array}{l}\text { An ecocity indicates a city in which ecology and health are } \\
\text { integrated and the health and vitality of humans and nature are } \\
\text { pursued. Register, considered that ecocities are ecologically healthy } \\
\text { cities that are compact, dynamic and energy conserving settlements } \\
\text { in harmony with nature. }\end{array}$ \\
Huang and Yang [5] & $\begin{array}{l}\text { An ecocity is a sustainable subsystem sharing a fair quota of car- } \\
\text { rying capacity in the global or regional ecosystems. Ecocities are } \\
\text { complex systems, with harmonious natural environments, just } \\
\text { societies, and efficient economies established based on ecological } \\
\text { principles and ideological living environments consisting of unique } \\
\text { humanistic coordination between human and nature and harmony } \\
\text { among people. }\end{array}$ \\
Ecocities refer to ecologically healthy cities in which economic, \\
social and natural systems are integrated to enable inhabitants to \\
lead high-quality and low impact lives. \\
The eco-city is an essential model to achieve sustainable develop- \\
ment, and the assessment of an eco-city, forms the quantitative basis \\
of eco-city planning, construction and management effectiveness.
\end{tabular}




\subsection{Ecocampus - greening campuses}

Translating the 'Ecocity' vision to a university campus, as small-scale replica of a city, is one of the challenges that have to face higher education institutions. There is a common understanding in the literature that a sustainable university campus implies a better balance between economic, social and environmental goals in policy formulation as well as a long-term perspective about the consequences of today's campus activities [8]. The Ecocampus model adds an innovative guide to articulate a structure, which has challenged the university community to commit to sustainability. The Ecocampus can also become a model for the external community by gathering and sharing effective ideas and practices. Universities can promote a positive image to the greater society that is increasingly concerned with the environmental movement. [2]

It is well-known that in a green campus operation, one of the important issues is the energy consumption, in order for "physical changes to existing built infrastructure and changes in the behavior of facility users that will lead to reduced energy use' [9]. On an Ecocampus model, 'planning can be helpful in securing American and European government funding to construct energy efficient green buildings and make use of renewable Aeolic-wind and heliacal-solar energy sources and photovoltaic parks. Most importantly, sustainability education provides an opportunity to teach young minds an open, socially responsible philosophy for earth, environment, forest, energy and water conservation' [10].

Transportation generates a series of direct and indirect effects that should occupy a central position in university policies [11]. For this reason, the research about the transportation, higher education and sustainability has increased in the last decade. Overall, the literature shows that 'only those students who live on campus walk as a principal mode of transportation to classes and even in this case, there are more students who use private vehicles. For students living off campus, automobiles are by far the principal choice of transportation. Buses are used by many students but bicycling is still fairly rare as a means of commuting' [12]. Therefore, sustainable transportation policies at the university need to continually reassess their outcomes. In line with the proposal by Kaplan [12] "there is significant potential for increasing the modal share of walking and cycling trips to the campus given the current figures" [11].

Another implication is water use on campuses, 'the water consumption reduction effort will have fulfilled its role of a precursor action toward the insertion of sustainability practices in the university' [13]. Finally, other aspects to merge sustainable development into policy and practice, is waste management. Universities generate thousands of tons of waste and this topic has become a key issue for institutions of higher education. The starting point is, separation and quantification of solid residual resources that contribute to the following fact, "It is thus essential to design and implement strategies that will minimize barriers to recycling and previous studies have suggested that a convenient infrastructure also plays a vital role" Kelly et al. (Kelly, Mason, Leiss, \& Ganesh, 2006) also, convenience in this case incorporates two factors: the distance to the collection spot where recyclables are carried to and the time spent on recycling activities [14].

\subsection{Urban and suburban campuses}

Any effort that is made to achieve sustainability must take into account that universities are unique places functioning in specific contexts [15]. Some of the contexts of the campuses 
where these institutions have locations are in the urban and suburban areas. While the universities and sustainability receive much attention in the literature, the context (where they integrate urban and suburban areas with universities and sustainability) is under investigated.

In the case of urban areas, universities and sustainability, a study "...evaluate the ecological footprint of an urban, public university in the United States" [16]. This way, an ecological footprint analysis (EFA) for the University of Illinois in Chicago (UCI) included "97,601 global hectares (2.66 global hectares per total faculty, staff and students). The ratio of ecological footprint to land area is very high for a highly urban university (UIC - 1005) as compared to a very rural university (Holmes Lacey College - 1.23)" [16]. A similar study published by Zhang et al. [14] "...Evaluate the ecological footprint of an ecological construction of a public university near urban centers. The institution was Xi' an University of Architecture and Technology from China (21,398 global hectares). Findings of the study say that 'compared to the large urban universities in North America, university campuses in China show similar high density of land use while appear lower consumption levels and utilization rate of resources' [14].

In the case of suburban areas, universities and sustainability, Miralles-Guash and Domene [11] analyses the transportation challenges of the Universidad Autónoma de Barcelona (UAB) campus which have arisen from implementing a sustainable transportation policy. These authors recognize that 'Universities are characterized by the fact that they represent a cross-section of the population from different socio-economic backgrounds and ages, generate irregular schedules and the constant movement of people throughout the day. This is even more noticeable in university campuses located in suburban settings: daily commuting of the university population, longer distances travelled and the predominance of private car use over non-motorized means of transportation' [11].

\section{METHODOLOGY}

The research questions are related to the experiences of sustainability policies on two different universities, one mostly urban in a historic city and the other mostly suburban to the outskirts of a large city. A case study method is used to explore the sustainability policies of two types of universities. A qualitative case study method is appropriate, because the aim of this study is to generate fresh and deeper insights into the universities about their sustainability policies relating to the area and the city in which they are located.

Data collection included five semi-structured interviews (with academics and the responsible of 'Ecocampus' offices), corporate reports and the public domain. We follow a case study research strategy by using a triangulation of various data sources [17]. QDA Miner software was used to analyze the transcriptions of interviews. This methodology allowed presenting the most relevant categories cited by respondents.

University 'A' refers to a case on an urban setting in one of the most important cities of Spain, which has been declared World Heritage by UNESCO as well, the institution, has more than 27,000 students and 5400 staff. It has three campuses where $60 \%$ of the university community is in downtown and the $40 \%$ is in the external campus.

University ' $\mathrm{B}$ ' is above all a suburban public university of Spain. With about 25,000 students, more than 2400 staff, University 'B' offers a comprehensive range of graduate and postgraduate studies in its eight faculties: seven in a suburban campus and one in an urban campus. 


\section{ANALYSIS OF THE RESULTS AND DISCUSSION}

\subsection{Urban University A}

- As for the importance of the university within city development, the Chief for the Office of General Affairs widely justified it by stating "University A is one of the biggest enterprises in the City". Furthermore, this university has occupied for many years a very important position on the UI Green Metrics ranking, being a green campus with some limitations, one of the most significant are their historical buildings, like the Chief's quote: “...An important issue is when the infrastructure is old, it can't even get certify with an important energy classification, because if the building its notrate with a specific energy classification, it won't get the certification". Additionally, the Chief indicated other barriers to consider in green campus operation:

- "To design a plan to change heaters or to adapt to better systems would take 15 years, like everyone knows the problem for universities is about budget, in the community, we all want a sustainable university but there is not enough money, so that we create a plan that can be afford with no money, or at least self-sufficient".

"At the external campus, which has the newest buildings, we had the opportunity to make a renewable energy sample of a biomass boiler, cogeneration of natural gas, photovoltaic solar energy, mini wind power generation"

\subsection{Suburban university B}

In line with the implementations for sustainable development strategies, the Ecocampus Office was founded in 1997 at university 'B'. The guidelines sustainability policies at University ' $\mathrm{B}$ ' are similar for the two campuses although the context was considered for its adaptation. In the case of sustainability policies related to water, suburban campus ' $\mathrm{B}$ ' has a wide ground for grass and despite measures such as drip irrigation lawn, the extension of grass is a variable that affects a considerable proportion of water consumption on campus.

This university has favored other technical measures for water management such as: 'that all taps have diffuser and that the cisterns have double switch. In addition, this university has tried other types of gardening and design of the city to rethink public space that is not only meadow grass, but also other materials that involve different types of maintenance and cleaning'. In short, the awareness of the university's community requires more effort than the technical measures. These technical measures are solved with more financial resources available.

An advantage of a suburban university as ' $\mathrm{B}$ ' is that fast visibility of sustainable initiatives. In fact, according to a professor of this university "... all people know each other and everything that you do has an immediate impact, such as: green week..." In the words of the person responsible for the Ecocampus office, 'communication between faculties of a suburban campus is interesting because when any conference is scheduled on any of the faculties, people can participate more easily than other types of campuses".

For a public institution of higher education, ' $\mathrm{B}$ ' is sensitive to environmental policies, although a professor of this university stated that these kinds of institutions need "a global institutional policy, with an awareness that extends all levels". 


\subsection{Descriptions of universities about Green Metrics}

According to 2015 IU Green Metrics the two universities 'A' and 'B' are in the best positions in the ranking amongst Spanish universities. However, there is a difference of 20 positions between urban university 'A' and the suburban university ' $\mathrm{B}$ '.

Figure 1, shows the results of each university 'A' and 'B' with a difference of about six GreenMetrics indicators. Overall, ranking by indicators show that sustainable policies in terms of education, transportation and energy-related indicators have better scores by the urban university, while the suburban university achieved the highest scores in the setting and infrastructure, water and waste indicators.

\subsection{Sustainability policies from ecocampus}

Figure 2 shows the frequency of the main key words which have been used regularlyin depth interviews, most of the time in both cases, the word 'campus' is mention in $24 \%$ of the conversation; also, 'suburban' is important to highlight the $12 \%$ of comments; the main idea in this type of campus is how new infrastructure can be a very interesting contribution to a green campus, the Chief of the department at university A declared "The University's energy consumption is $50 \%$ of thesuburban campus", as well as the person responsible of Ecocampus' office at university B added "advantage of being a suburban university is the good communication between faculties and buildings, we are like a small city where all the community knows each other, and everything has a big impact, also the access to our campus is easier than other type of campus..." The two views are interesting and illustrate that there are some considerable evident differences between an urban campus and suburban one according to the settings and context.

With respect to Fig. 3, the software has been selected a second group of words which are less frequent than the ones shown on Fig. 2. However, not less relevant, transportation, sus-

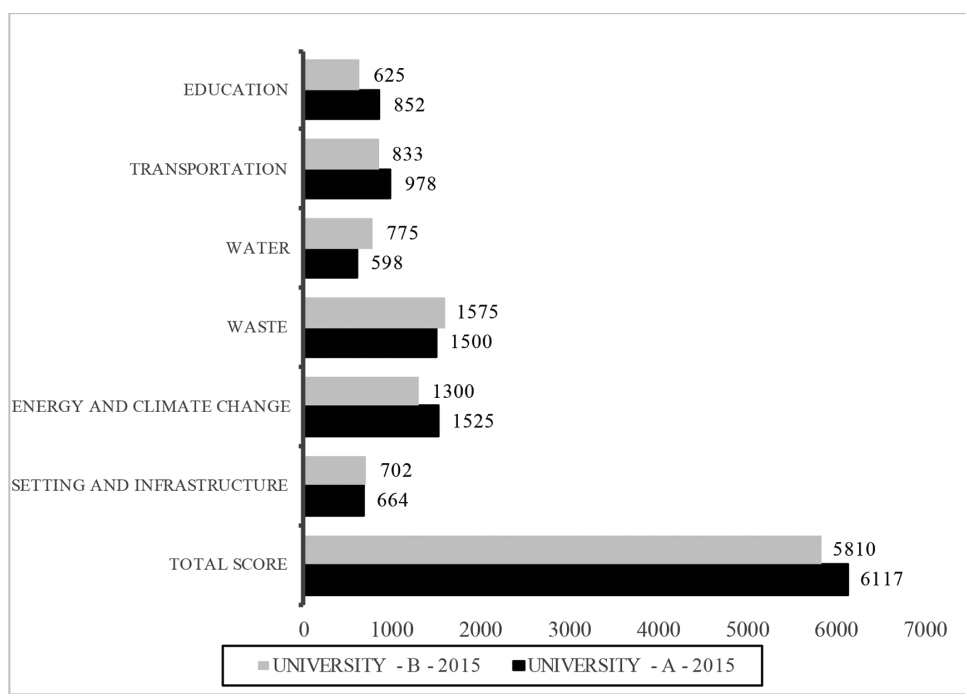

Figure 1: Comparative UI green metrics indicators. 


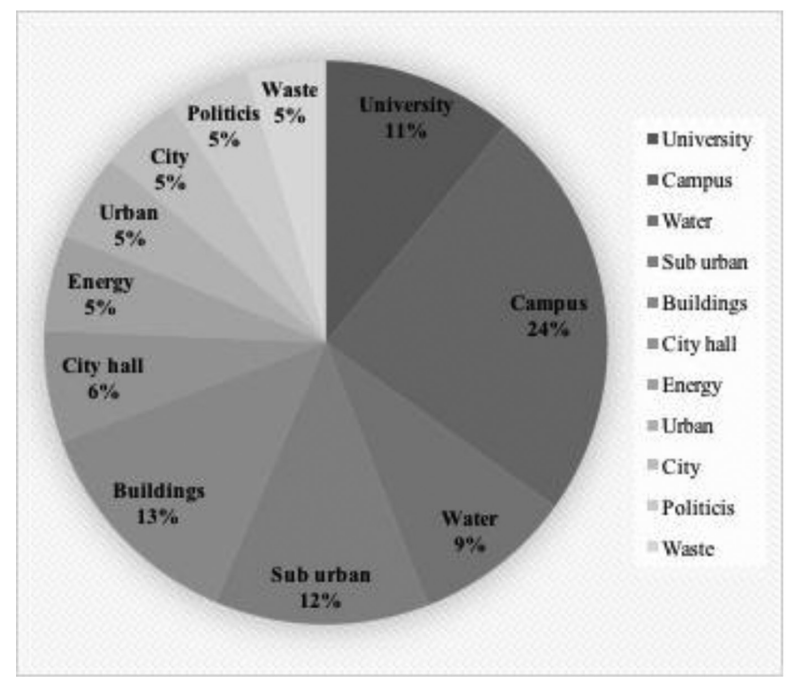

Figure 2: Frequency of key words - topics.

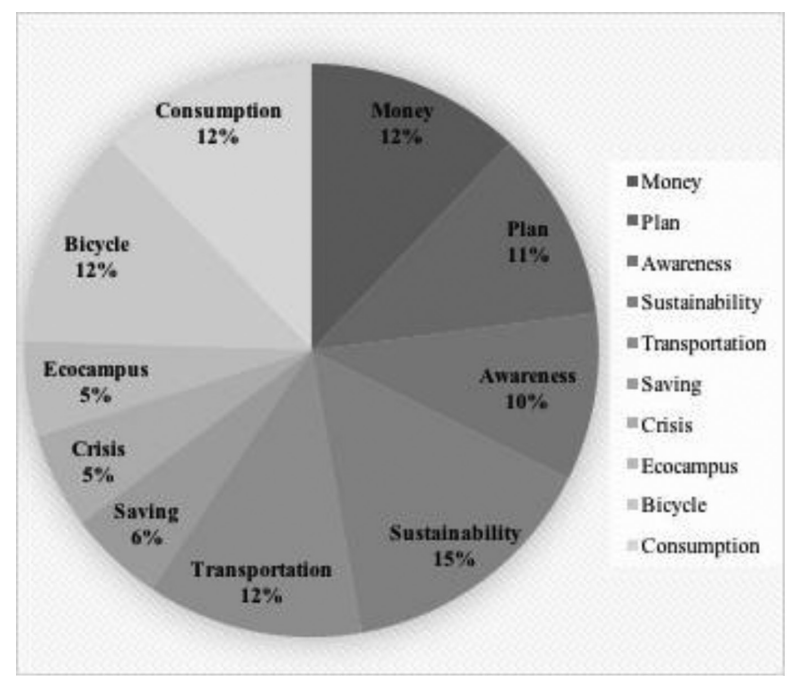

Figure 3: Frequency of key words - Sub topics.

tainability, consumption and money are concepts that have been emphasized. "The people's quality of life whom live in the same city where the university is make a difference, the community can move around the city at the same time as the university campus; nevertheless, to move by vehicle is more difficult, because of being in a historical city. There is not enough parking spaces inside the city." - said the person interviewed from University A. As opposed to university A's person interviewed, the person interviewed from University B said "there are not limitations for transportation by car". Nevertheless, both universities agree that transportation is a challenge to improve. Additionally, there is a relation between sustainability and 


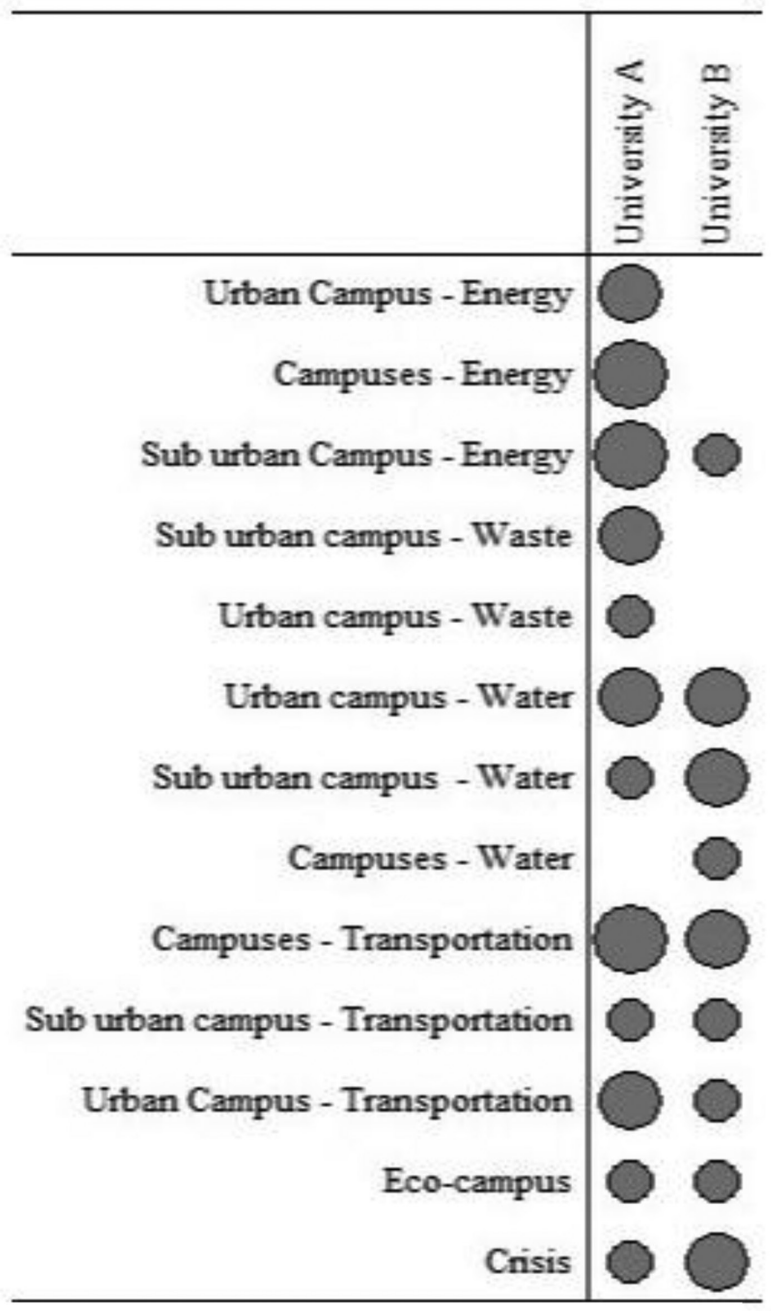

Figure 4: Frequency of codes.

economic resources, "the economic crisis has made it a challenge to be sustainable as well as prioritizing budget decisions" interviewees of university A said, and people from university B also said "the country's crisis have affected green initiatives".

In this context, the answers about the sustainability of their campus are focus in same UI Green Metrics indicators; Fig. 4 describes a clear idea of a reference of every type of campus, urban, suburban and campuses to refer for both campuses (urban and suburban). Suburban campus in University B is notable in water indicator, as a consequence of its environment. The optimization of water consumption is based on the correlation with the university's community awareness and the green areas of the campus. "The awareness is a very complicated problem, in summer when the grass is not green there are a lot ofemails asking what happen with the irrigation of the gardens, not everybody is aware of spending water" - responsible from University B's Ecocampus. Another substantial benefit is the encouraging 
waste indicator. This suburban campus is responsible for the completed waste management system, because the source of water comes to the campus without any purification treatment.

Whereas University A's strength is energy while it has limitations energy efficiency and conservation is an initiative that has been strongly focus to improved building's technology, also incorporating academic programs for students to learn with its renewable energy equipment. "A student may be taught in how this technology works" - interviewee from university A.

Based on our findings from the literature study to be an Ecocampus, an important characteristic for the reduction of energy use is to built sustainability infrastructures and establish performance improvement programs under capital constraints, Faghihi et al. [9] "focus in physical changes and changes in the behavior of facility users that will lead to reduced energy use". Also, Petratos and Damaskou [10] to take a model of green energy efficient buildings with some renewable energy sources which are the key to provide sustainable education as well as University 'A' does.

Literature compiled some of the more common models of transportation in a university community have a "...significant potential for increasing the modal share of walking and cycling trips..." [12], and this is a potential strategy in both cases of universities where the Ecocampus offices have bicycle programs; according to Fig. 3, bicycle is a relevant subtopic classified for both universities interviewed as an outstanding task to improve.

In this framework, strategies conservation actions were selected based on each case, and whether the literature cases measured water consumption control adopted by each campus setting [13]. On one hand, the City Hall's water management saves operations' budget, and meanwhile, in a suburban campus, the institution is responsible to make water drinkable and all the purification system, representing high cost.

\section{CONCLUSIONS}

In this paper, we began by acknowledging that Ecocity is one of the main sustainability challenges faced by today's society and how this vision is applied, under the Ecocampus concept, to the sustainable policies on university campuses. The main initiatives are related with energy and water consumption, transportation and mobility and waste reduction and recycling processes.

The current work has examined the experiences of sustainability policies of two different campuses of Universities in Spain, one urban setting in a historic city (University ' $A$ ') and the other suburban setting in the outskirts of a large city (University 'B').

The main lesson derived from the analysis of these case studies is that urban university ' $\mathrm{A}$ ' has encouraged the economic and social development of the city, while the suburban university ' $\mathrm{B}$ ' has greater autonomy with a reduced impact in the local settlements.

Overall, the results of university 'A' and 'B' about Green Metrics indicators and with the depth interviews, indicated that sustainable policies in terms of energy indicators have better scores by the urban university, but this kind of campus has limitations with historical infrastructure, while the suburban university has better outcomes in the water and waste management. Both universities need to improve the sustainability policies of the transportation.

The guidelines for sustainability policies for Universities 'A' and 'B' are similar for both campuses. However, there are aspects such as, location and the economic resources of the university, which have a direct effect on adaptation measures of sustainability policies.

Ecocity and Ecocampus have similar challenges from different scales. In fact, both concepts are inter-related, because both administrations, local and university, should work in 
194 Urban Regeneration and Sustainability

coordination to cope with the environmental problems that they have to face. This exploratory study offers the local authorities and the academic community some interesting environmental experiences in university campus.

\section{ACKNOWLEDGEMENTS}

This research was supported by the project "Research on energy efficiency and sustainable transport in urban areas: analysis of scientific development and the social perception of the subject from the perspective of metric information studies" (CSO2014-51916-C2-1-R). Spanish Ministry of Economy and Competitiveness (2015-2018).

\section{REFERENCES}

[1] Jun Zhu, D.X., City School Books-Eco-city Theory, China Social Sciences Press: Beijing, China, 2000.

[2] Finlay, J. \& Massey, J., Eco-campus: applying the ecocity model to develop green university and college campuses. International Journal Sustainability in Higher Education, 13(2), pp. 150-165, 2012. http://dx.doi.org/10.1108/14676371211211836

[3] Alshuwaikhat, H.M. \& Abubakar, I., An integrated approach to achieving campus sustainability: assessment of the current campus environmental management practices, Journal of Cleaner Production, 16(16), pp. 1777-1785, 2008. http://dx.doi.org/10.1016/j.jclepro.2007.12.002

[4] Register, R., Ecocity Berkeley: Building Cities for a Healthy Future, North Atlantic Book: Berkeley, CA, 1987.

[5] Huang, Z.Y. \& Yang, D.Y., The theoretical approach of the ecological city. City Planning Review, 25(1), pp. 59-66, 2001.

[6] Liao, Y.T. \& Chern, S.G., Strategic ecocity development in urban-rural fringes: analyzing wulai district. Sustainable Cities and Society, 19, pp. 98-108, 2015. http://dx.doi.org/10.1016/j.scs.2015.07.014

[7] Wang, Y., Ding, Q. \& Zhuang, D., An eco-city evaluation method based on spatial analysis technology: A case study of Jiangsu Province, China. Ecological Indicators, 58, pp. 37-46, 2015.

http://dx.doi.org/10.1016/j.ecolind.2015.05.032

[8] Newman, L., Change, uncertainty, and futures of sustainable development.Futures, 38(5), pp. 633-637, 2006.

http://dx.doi.org/10.1016/j.futures.2005.09.011

[9] Faghihi, V., Hessami, A.R. \& Ford, D.N., Sustainable campus improvement program design using energy efficiency and conservation. Journal of Cleaner Production, 30, pp. 1-10, 2014.

[10] Petratos, P. \& Damaskou, E., Management strategies for sustainability education, planning, design, energy conservation in California higher education. International Journal of Sustainable in Higher Education, 16(4), pp. 576-603, 2015. http://dx.doi.org/10.1108/IJSHE-03-2014-0038

[11] Miralles-Guasch, C. \& Domene, E., Sustainable transport challenges in a suburban university: The case of the Autonomous University of Barcelona. Transport Policy, 17(6), pp. 454-463, 2010.

http://dx.doi.org/10.1016/j.tranpol.2010.04.012 
[12] Kaplan, D.H., Transportation sustainability on a university campus. International Journal of Sustainable in Higher Education, 16(2), pp. 173-186, 2015. http://dx.doi.org/10.1108/IJSHE-03-2013-0023

[13] Marinho, M., do Socorro Gonçalves, M. \& Kiperstok, A., Water conservation as a tool to support sustainable practices in a Brazilian public university. Journal of Cleaner Production, 62, pp. 98-106, 2014. http://dx.doi.org/10.1016/j.jclepro.2013.06.053

[14] Zhang, J., Liu, J., Liu, W., Wang, L., Shi, H. \& Du, H., Comparative analysis of ecological footprint on ecological campus of a Urban University in China. Advanced Materials Research, 616-618, pp. 1085-1089, 2013. http://dx.doi.org/10.4028/www.scientific.net/AMR.860-863.1085

[15] Tolley, R., Green campuses: cutting the environmental cost of commuting. Journal of Transport Geography, 4(3), pp. 213-217, 1996. http://dx.doi.org/10.1016/0966-6923(96)00022-1

[16] Klein-Banai, C. \& Theis, T.L., An urban university's ecological footprint and the effect of climate change. Ecological Indicator, 11, pp. 857-860, 2011. http://dx.doi.org/10.1016/j.ecolind.2010.11.002

[17] Yin, R.K., Case Study Research: Design and Methods, Sage publications, 2003. 